\title{
Clinico pathological study of thyroid lesions in a rural tertiary care centre
}

\author{
Gaikwad S. L. ${ }^{1}$, Bhokare S. B. ${ }^{2}$, Deshmukh V. V. ${ }^{3}$, Dhillon M. ${ }^{4}$, Kale S. M. ${ }^{5}$ \\ ${ }^{1}$ Dr.Sheela Lakshmanrao Gaikwad, Associate Professor, ${ }^{2}$ Dr. Santosh Baliram Bhokare, Assistant Professor, ${ }^{3}$ Dr.Vaibhav \\ Vilas Deshmukh, Assistant Professor, ${ }^{4}$ Dr. Mona Dhillon, JR-2, ${ }^{5}$ Dr. Shivkanya Marotrao Kale, JR-2, all authors are \\ affiliated with Department of Pathology, SRTR Government Medical College, Ambajogai, Maharashtra, India.
}

Corresponding Author: Dr. Santosh Baliram Bhokare, Email: santy358@yahoo.co.in

\begin{abstract}
Objective: Present study is clinic pathological study of thyroid lesions in a rural tertiary care Centre. Thyroid lesions are fairly common world wide and are commonly encountered in clinical practice in rural areas also. It causes more concern because of high probability of malignancy in solitary thyroid nodules. Materials and Methods: Prospective study done in Dept. of pathology over a period of 6 months in a rural tertiary care centre. It included clinical examination, routine investigations and histo pathological diagnosis. Result: In our study of 40 cases, 31 were diagnosed as non-neoplastic and 9 as neoplastic. Most common clinical presentation was midline neck swelling, commonly on right side and majority of patients were diagnosed with colloid goitre (62.5\%) followed by multinodular goitre $(20 \%)$ on ultra sonography. The non-neoplastic to neoplastic ratio of 3.4:1. with female to male ratio of 19:1. Colloid goitre was the most common non neoplastic lesion and follicular adenoma was the most common neoplastic lesion. Conclusion: In current study conducted in a rural tertiary care centre, thyroid lesions were common in age group of $3^{\text {rd }}$ to $5^{\text {th }}$ decade with female predominance. Benign lesions were common than neoplastic lesions. Histopathological diagnosis of thyroid lesions is important for early diagnosis and treatment of neoplastic lesions.
\end{abstract}

Keywords: thyroid, malignancy, hyperplastic.

\section{Introduction}

Thyroid lesions are fairly common world wide and are commonly encountered in clinical practice [1]. The problem in clinical practice is to distinguish reliably the few malignant tumors from the many harmless nodules so that a definitive preoperative tissue diagnosis of the malignancy allows planning of appropriate surgery and relevant patient counselling. The prevalence of thyroid swelling ranges from $4 \%$ to $10 \%$ in the general adult population and from $0.2 \%$ to $1.2 \%$ in children [2].

They constitute only $0.7 \%$ of all cancers in female and $0.2 \%$ in males. The majority of clinically diagnosed thyroid swelling are non-neoplastic; only 5\% to $30 \%$ are malignant and require surgical intervention[3]. Thyroid lesions may be developmental, inflammatory, hyper plastic and neoplastic. The surgical excision of the nodule and its histological examination is the only way to differentiate between the more frequent benign and much less frequent malignant nodules [4].

Manuscript received: $14^{\text {th }}$ January 2018

Reviewed: $24^{\text {th }}$ January 2018

Author Corrected: $29^{\text {th }}$ January 2018

Accepted for Publication: $3^{\text {rd }}$ February 2018
A solitary thyroid nodule is defined as a palpable single, clinically detected nodule in the thyroid. It causes more concern because of high probability of malignancy in it, which can range from $5-35 \%$ of all solitary thyroid nodules [5]. Diffuse thyroid lesions are those that are associated with conditions affecting entire gland such as hyper plasia and thyroiditis. Nodular lesion comprises those disorders that produce a clinical nodule and consists of non-neoplastic hyper plasia as well as benign and malignant tumors [6]. Current study is about thyroid lesions in rural tertiary care centre conductedover a period of six months, this will help in obtaining recent data of thyroid lesions and its prevalence in patients presenting to a rural tertiary care centre.

\section{Materials and methods}

Type of study: Prospective, observational and descriptive.

Place of study: Department of pathology, SRTRGMC Ambajogai. 


\section{Original Research Article}

Duration of study: 6 months period from July 2017 to December 2017

Sample collection and methods: In this study we have included hemithyroidectomy, sub total thyroidectomy and total thyroidectomy specimens received in department of pathology. Complete clinical history, along with ultra sonographic (USG) findings and related investigations were taken into consideration.

Inclusion criteria: Hemithyroidectomy, subtotal thyroidectomy and total thyroidectomy specimens received for histo pathological examination suspected for neoplastic and non-neoplastic lesions of thyroid.

Exclusion criteria: Nil

\section{Results}

In present study, 40 cases of thyroid specimens for histo pathological examination were studied. 30 cases were (75\%) were adults $25-50$ yrs., followed by elder (50-75yrs) patients 8 cases $(20 \%)$ and 2 cases of young patients (0-25yrs) (Table-01).

Out of 40 patients $38(95 \%)$ were females and 2 (5\%) were males, F: M ratio was 19:1. This shows female predominance (Table 02).

All the 40 patients $(100 \%)$ presented with midline neck swelling were followed by menstrual irregularity (5\%) and dyspnoea (5\%). Out of 40 cases, $20(50 \%)$ patients presented with thyroid swelling involving right lobe followed by 15 patients $(37.5 \%)$ involving left lobe and 5 patients (12.5\%) presented with diffuse thyroid swelling (Table 03).



Figure.-1: Hashimoto's thyroiditis (H \& E, 40x): Photomicrograph showing hurthle cell change and lymphoid follicle with active germinal centre.

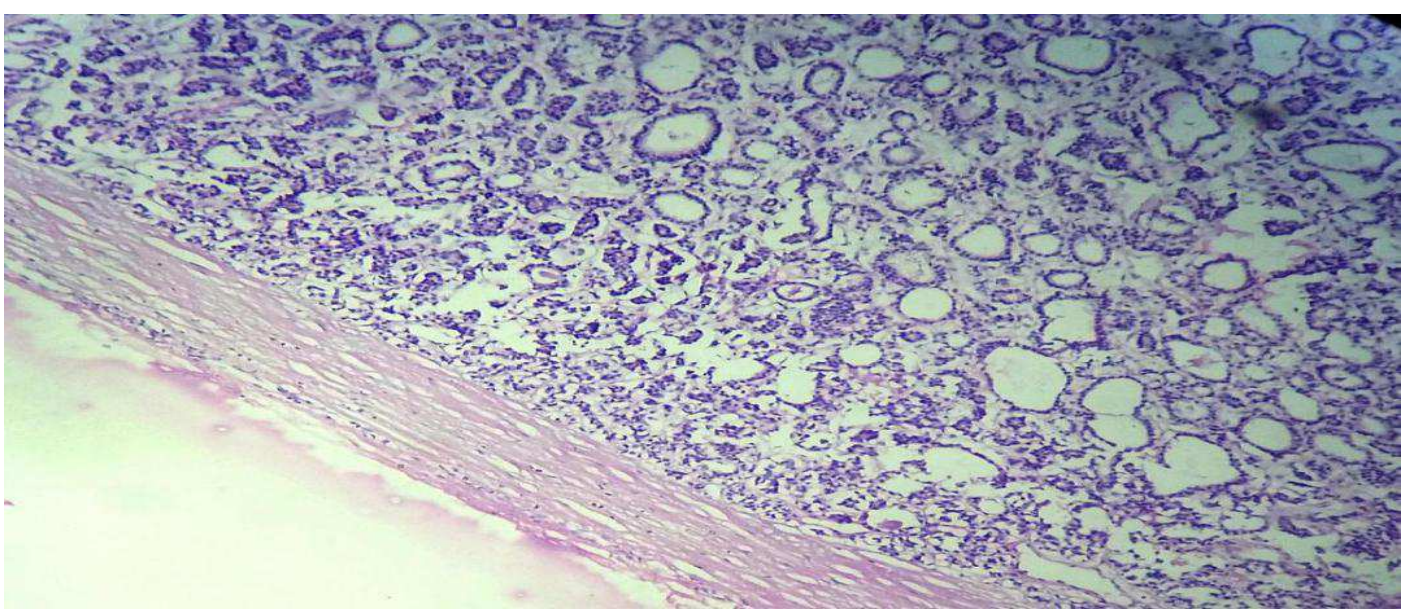

Fig-2: Follicular adenoma (H\&E, 10x): photomicrograph showing fibrocollagenous capsule underneath thyroid follicles arranged in microfollicular pattern lined by flattened to cuboidal epithelium. 




Fig-3: Papillary thyroid carcinoma $(H \& E, 10 x)$ : photomicrograph showing well formed branching papillae.

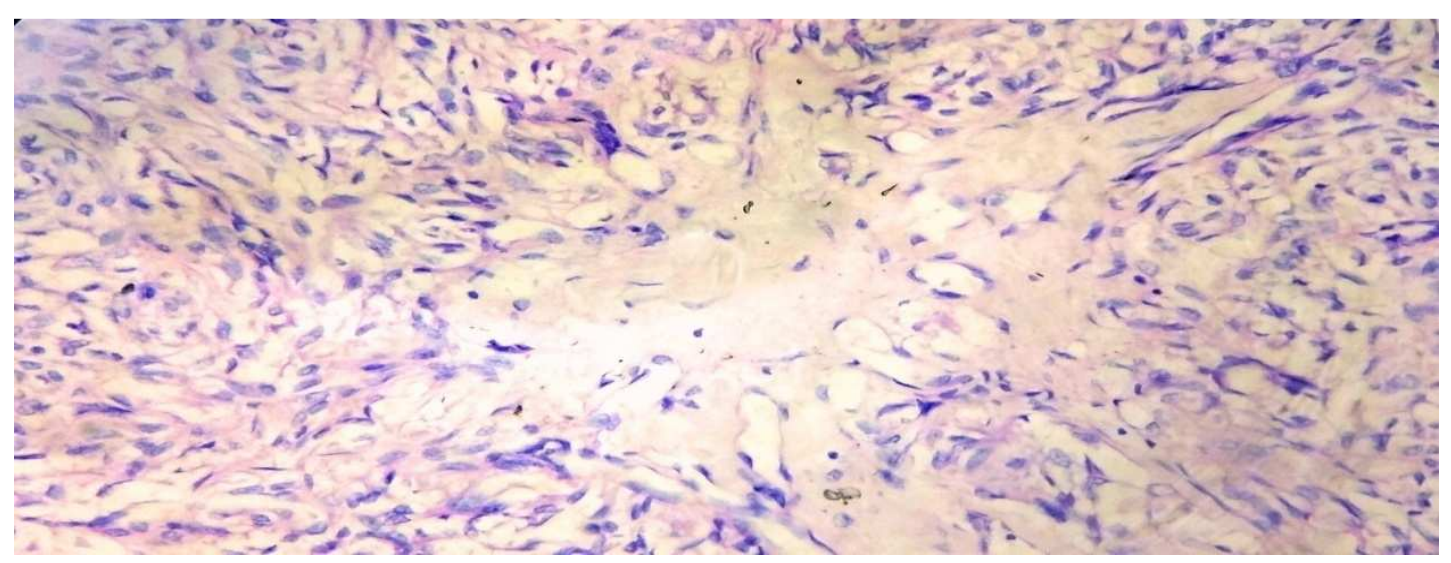

Fig-4: Medullary carcinoma (H\&E, 40x): Photomicrograph showing oval to spindle tumour cells having hyperchromatic nuclei and amyloid stroma

Table- 01: Age wise distribution of thyroid lesions.

\begin{tabular}{|c|c|c|}
\hline Age (years) & No of cases & Percentage of cases $(\%)$ \\
\hline $0-25$ & 02 & 05 \\
\hline $26-50$ & 30 & 75 \\
\hline $51-75$ & 08 & 20 \\
\hline
\end{tabular}

Table -02: Sex wise distribution of thyroid lesions.

\begin{tabular}{|c|c|c|}
\hline Sex & No of cases & Percentage of cases $(\%)$ \\
\hline Female & 38 & 95 \\
\hline Male & 02 & 05 \\
\hline Total & $\mathbf{4 0}$ & $\mathbf{1 0 0}$ \\
\hline
\end{tabular}

Table- 03: Clinical symptoms in cases with thyroid lesions.

\begin{tabular}{|c|c|c|}
\hline Clinical symptoms & No of cases & Percentage of cases $(\%)$ \\
\hline Midline neck swelling & 40 & 100 \\
\hline Menstrual irregularity & 02 & 05 \\
\hline Dyspnoea & 02 & 05 \\
\hline Hoarseness of voice & 01 & 2.5 \\
\hline
\end{tabular}


Original Research Article

Table- 04: USG findings in thyroid lesions.

\begin{tabular}{|c|c|c|}
\hline USG finding & Number of cases & Percentage of cases $(\%)$ \\
\hline Colloid goitre & 25 & 62.5 \\
\hline Multinodular goitre & 08 & 20 \\
\hline Solitary thyroid nodule & 05 & 12.5 \\
\hline Thyroiditis & 02 & 5 \\
\hline
\end{tabular}

Table-05: Distribution of non-neoplastic and neoplastic lesions of thyroid.

\begin{tabular}{|c|c|c|c|}
\hline Thyroid lesions & Histopathological diagnosis & No. Of cases & $\begin{array}{c}\text { Percentage of cases } \\
(\%)\end{array}$ \\
\hline \multirow{3}{*}{ Non-neoplastic } & Simple colloid goitre & 22 & 55 \\
\cline { 2 - 4 } & Multinodular goitre & 05 & 12.5 \\
\cline { 2 - 4 } & Hashimoto's thyroiditis & 03 & 2.5 \\
\cline { 2 - 4 } & Haemorrhagic cyst & 01 & 15 \\
\hline \multirow{3}{*}{ Neoplastic } & Follicular adenoma & 06 & 2.5 \\
\cline { 2 - 4 } & Follicular carcinoma & 01 & 2.5 \\
\cline { 2 - 4 } & Papillary carcinoma & 01 & 2.5 \\
\cline { 2 - 4 } & Medullary carcinoma & 01 & 2.5 \\
\hline
\end{tabular}

All patients in our study underwent ultrasonography where the majority of patients were reported with colloid goitre $(62.5 \%)$ followed by multinodular goitre $(20 \%)$, solitary thyroid nodule $(12.5 \%)$ and thyroiditis $(5 \%)$ (Table 04$)$.

In our study of total 40 cases, 31 cases (77.5\%) were diagnosed as non-neoplastic and remaining 9 cases $(22.5 \%)$ as neoplastic. Among non-neoplastic lesions simple colloid goitre 22 cases (70.97\%) was found to be the most common followed by multinodular goitre 5 cases (16.2\%), Hashimoto'sthyroiditis (7.5\%) and haemorrhagic cyst (2.5\%). Among neoplastic cases follicular adenoma 6 cases $(66.7 \%)$ was found to be the most common followed by follicular carcinoma (1), papillary carcinoma (1) and Medullary carcinoma (1). Ratio of non -neoplastic to neoplastic lesions is 3.4:1 (Table $05)$.

\section{Discussion}

Present study was conducted in Department of Pathology, SRTR GMC Ambajogai over a period of 6 months from July 2017 to December 2017. All the specimens of thyroid i.e. hemithyroidectomy, subtotal and total thyroidectomy which were sent for histopathological examination were considered for this study.

Diseases of thyroid are of great importance because most are amenable to medical or surgical treatment [13]. It is known that approximately $1-10 \%$ adults in USA ae reported to have solitary thyroid nodules [14, $15,16]$.

Single nodules are four times more common in women than in men and its incidence increase throughout life benign lesion outnumber malignant lesions by ratio of $10: 1[14]$. Overall incidence of thyroid malignancy is low $0.5-1.0 \%$ of all cases and 3.3 to $17 \%$ of all thyroid cases $[14,15,16]$.
In our study, age of patients ranged from 16-75 years with mean age of 45 years. Findings of present study correlate with that of studies conducted by other Indian authors [7, 8].

In our study out of total 40 cases, 38 were females $(95 \%)$ and 2 were males (5\%) with F: M ratio of 19:1 which correlates with studies by other authors $[8,9,13$, 17].

Almost all of the patients in present study presented as midline neck swelling. Few of the patients presented with dyspnoea $(5 \%)$ and hoarseness of voice $(5 \%)$. In study conducted by Prakash A et al thyroid swelling was in 95.5\% cases [11] and Godinho-Matos L et al, the thyroid swelling was present in $100 \%$ cases, dyspnoea in $3 \%$ cases and hoarseness of voice in 3\% cases [12].

Thus findings of present study correlate with studies conducted by other authors. 


\section{Original Research Article}

In current study out of total 40 cases, $20(50 \%)$ cases presented with right lobe involvement, 15 cases $(37.5 \%)$ with left sided thyroid swelling and remaining 5 cases $(12.5 \%)$ with diffuse thyroid swelling which correlates with study conducted by Gupta et al[4].

USG is used to establish physical characteristics like size, shape and number of nodules [4]. In our study colloid goitre 25 cases $(62.5 \%)$ was the most common finding on USG followed by multinodular goitre 8 cases (20\%). Similarly study conducted by Gupta et al, multinodular goitre $(55 \%)$ was the most common ultrasonographic finding followed by solitary thyroid nodule (19\%) [4]. In our study most common lesions were non neoplastic $31(77.5 \%)$ and remaining were neoplastic $09(22.5 \%)$ with non-neoplastic to al neoplastic ratio of 3.4:1. Similar findings reported by other authors Magdalene et al [13] and Abdul Gafoor etal [17].

Among non-neoplastic lesions, colloid goitre was the most common lesion 22 cases $(70.97 \%)$ followed by multinodular goitre 05 cases $(16.2 \%)$. Magdalene et al noted colloid goiter (42\%) was the most common lesion in their studies [13] and Kusum et al, as multinodular goiter $(73 \%)$ followed by adenomatous goiter $(8 \%)$ [15]. Among neoplastic cases follicular adenoma 06 cases $(66.7 \%)$ was the most common lesion followed by one each case of Follicular carcinoma, Papillary carcinoma and Medullary carcinoma. Similar results were noted by Abdul Gafoor et al and Sapna et al [17,18]. Overallbenign lesion were more common than malignant lesions and findings of present study correlate with other studies $[9,10]$.

As our centre is rural tertiary care centre, very few patients of malignancy are reported. Because most patients are referred to higher centre, the incidence of papillary carcinoma, medullary carcinoma and follicular carcinoma are less. Also there is high illiteracy, lack of knowledge and importance about health problems the patients ignore the symptoms of disease and present late to the institute. This maybe the reason for lower incidence of malignant lesions and mostly non neoplastic lesions in present study.

\section{Conclusion}

Thyroid lesions are fairly common in females of young age group. Also the incidence of thyroid lesions is increasing in rural population. The thyroid gland may be affected with various disorders. Thyroidectomy may have both therapeutic and diagnostic value. in present study, thyroid lesions were most common in age group of 3 rd to 5 th decade with female predominance. In present study colloid goitre was the most common non neoplastic lesion and follicular adenoma was the most common neoplastic lesion. Combined opinion on nature of thyroid lesion should be done based on history, clinical examination and ultra sonographic features. Early diagnosis by FNAC and excision of lesion will provide comfort for the patient and also decrease the problems arising from malignant lesions.

Present study describes the current data on thyroid lesions in rural tertiary care centre and will help clinicians in diagnosing the lesions. Also present data will help in understanding the occurrence of disease in rural population and may help in creating awareness in public regarding the thyroid lesions and help in early diagnosis and treatment of these lesions.

Funding: Nil, Conflict of interest: None initiated, Permission from IRB: Yes

\section{References}

1. Tsegaye, B., \&Ergete, W. Histopathologic pattern of thyroid disease. East African Medical Journal, 2003; 80 (10),525-528.http://doi.org/10.4314/eamj.v80i10.8755

2. Burch, H. B., Burman, K. D., Reed, H. L., Buckner, L., Raber, T., \& Ownbey, J. L. Fine needle aspiration of thyroid nodules: Determinants of insufficiency rate and malignancy yield at thyroidectomy. Acta Cytologica, 1996; 40(6), 1176-1183. http: //doi.org/10.1159/000 333977

3. Gharib, H., \&Goellner, J. R. Fine-needle aspiration biopsy of the thyroid: An appraisal. Annals of Internal Medicine.1993; http://doi.org/10.7326/0003-4819-1184-199302150-00007

4. Gupta A, Jaipal D, Kulhari S, Gupta N. Histopathological study of thyroid lesions and correlation with ultrasonography and thyroid profile in western zone of Rajasthan, India. Int J Res Med Sci 2016; 4:1204-8.

5.Ananthakrishnan N, Rao KM, Narasimhans R, Veliath, Smilet SR, Jagadish S. The Single Thyroid Nodule: A South Indian Profile of 503 Patients with Special Reference to Incidence of Malignancy. Indian J Surg. 1993; 55(10):487-92.

6. Baloch, Z. W., \&Livolsi, V. A. Pathology of Thyroid and Parathyroid Disease. In Stenberg's d Diagnostic Surgical Pathology 2015. (pp. 533-594). 


\section{Original Research Article}

7. Chowdhary Jyoti, A study of thyroid nodules: Diagnostic correlation between fine needle aspiration cytology and histopathology; J Indian Med Assoc 2008; 106 (6): 389-390.

8. Hanumanthappa M. B., Gopinathan S., Rithin Suvarna, Guruprasad Rai D., Gautham Shetty. The Incidence of Malignancy in Multi-nodular Goitre: A Prospective Study at a Tertiary Academic Centre. Journal of Clinical and Diagnostic Research. 2012; 6 (2): 267-270.

9. Akerman Mans, Tennval Ian, Biorklund Anders Martensson Hans, Moller Torgil. Sensitivity\& Specificity of Fine Needle Aspiration Cytology in the diagnosis of Tumors of thyroid Gland, Acta cytological 1985; 29 : 850 - 854 .

10. Mazzaferri E.L. Management of Solitary Thyroid Nodule (Current concepts) The New England Journal of Medicine 1995; 328(8):553-559.

11. Prakash A, Moulik BK, Sharma LK, Kapur M, Poddar PK. Carcinoma of thyroid gland. A clinical study. Ind J Surg. 1974; 43:409-16.

12. Godinho-Matos L, Kocjan G, Kurtz A. Contribution of fine needle aspiration cytology to diagnosis and management of thyroid disease. J ClinPathol. 1992; 45:391-5.
13.K.F. Magdalene, Jose Swetha, Navya Narayanan, B Sumangala. Histopathological study of thyroid lesions in a tertiary care center in coastal belt of South India. Trop J Path Micro 2017; 3(1):77-83.doi: 10.17511/ jopm. 2017.i1.14.

14. Darwish, A. H., Sindi, K. A. Al, \&Kafsi, J. El. Bahrain Med Bull 2006; 28(4): 4-9.

15. Borsaikia K, Patar M.Clinicopathological Study of Thyroid Swellings with Some Emphasis on Geographical and Community Distribution: A Hospital Based Analysis. Bengal Journal of Otolaryngology and Head Neck Surgery 2016; 24(2):1-6

16. A. Elhamel, I. H. Sharif and S. A. Wassef. The Pattern of Thyroid Disease in a Closed Community of 1-1/2 Million People. Saudi Medical Journal, Vol. 9, No. 5, 1988, pp. 481-484.

17. Ghafoor, A., Sajjad, M.,Akram, M., \& Khan, Z. A. Histopathological Pattern of Enlarged Thyroid Gland. Gomal Journal of Medical Sciences, 2015;13(4), 2-5.

18. Patel, S., \& Harish, S. Cytohistological Correlation of Thyroid Lesions with Special Emphasis on Recent Trends, 2016;3(10), 1-5. https://doi.org/10.17354/ ijss/ 2016/19.

\section{How to cite this article?}

Gaikwad S. L, Bhokare S. B, Deshmukh V. V, Dhillon M, Kale S. M. Clinico pathological study of thyroid lesions in arural tertiary care centre. Trop J Path Micro 2018;4(1):40-45.doi: 10.17511/jopm.2018.i1.07. 